\title{
Pesticide Traders' Perception of Health Risks: Evidence from Bangladesh
}

\author{
by \\ SUSMITA DASGUPTA \\ CRAIG MEISNER \\ Development Economics Research Group \\ The World Bank \\ NLANDU MAMINGI \\ Department of Economics \\ University of the West Indies \\ Cave Hill Campus, Barbados
}

\begin{abstract}
As pesticide traders are important sources of information about the health impacts of pesticides, a crucial understanding of their perception is necessary to guide further pesticide information dissemination efforts through this channel. To this end, a 2003 survey of 110 Bangladeshi pesticide traders was conducted with questions on the pesticides in stock, knowledge and training in pesticide use and handling, sources of information, protective measures and health effects. A two-equation bivariate probit model was initially estimated for health impairment and trader perception with health effects as an endogenous regressor in the perception equation. Results indicate that pesticide toxicity, exposure in terms of number of years spent in pesticide business, trader's age (experience) and the interaction between the most harmful pesticides and training received in pesticide use and handling were the significant determinants of health impairment status. Risk perception was determined by actual health impairment status, pesticide toxicity, the average number of hours spent in the shop per day, training and the interaction term between highly toxic substances and training. The evidence suggests that the current information content may not be effective, and thus training programs should be revised with a greater emphasis on health hazards and averting behavior.
\end{abstract}

Keywords - Trader, pesticide exposure, health impairment, health risk perception, Bangladesh

World Bank Policy Research Working Paper 3777, November 2005

The Policy Research Working Paper Series disseminates the findings of work in progress to encourage the exchange of ideas about development issues. An objective of the series is to get the findings out quickly, even if the presentations are less than fully polished. The papers carry the names of the authors and should be cited accordingly. The findings, interpretations, and conclusions expressed in this paper are entirely those of the authors. They do not necessarily represent the view of the World Bank, its Executive Directors, or the countries they represent. Policy Research Working Papers are available online at http://econ.worldbank.org.

Correspondence should be addressed to: Susmita Dasgupta, MC2-205, World Bank, 1818 H Street, NW, Washington, DC 20433, Sdasgupta@worldbank.org. 


\section{Summary}

Recent survey evidence suggests that pesticide traders or retailers are an important source of information on the potential health risks of pesticides to farmers. This is particularly true in developing countries where access to such information may often be concentrated in relatively few hands. As conduits of this information, it would be important to better understand the behavior, knowledge and training habits of traders such that policymakers can easily identify and target informational gaps for more effective pesticide information campaigns. More specifically, it would be of value to know what shapes a traders' risk perception of pesticides and to then to focus capacity building efforts in these areas.

In this study we surveyed 110 Bangladeshi pesticide traders (shops) for pesticides in stock, knowledge and training in pesticide use and handling, sources of information, protective measures and health effects. With this information, we proceeded in two steps. First we constructed an equation to determine what may explain the health status of pesticide traders. We then constructed a second equation of risk perception, containing the health status variable, and estimated this simultaneously with the first. Results for the health effects equation reveal that health status is significantly associated with the amount of toxic inventory, number of years in business, trader experience and the interaction between highly toxic stock and training. This suggests that increases in exposure to toxic pesticides, on a repeated basis, for many years, leads to adverse health conditions experienced by pesticide traders. However, as a traders' experience with pesticides increases, as does his awareness about the potential risk hazards, this tends to decrease the prevalence of adverse health outcomes; perhaps through averting behavior.

Estimation of the second equation of pesticide risk perception revealed significant associations with a traders' health status, the amount of toxic pesticides in stock, the number of hours spent in the shop per day, pesticide use training and the interaction between highly toxic stock and training. This suggests that a trader is more aware of the inherent risks the greater the number of health impairments experienced, the greater the 
amount of toxic pesticides in stock, the greater the number of hours spent in the shop and if the trader was trained in pesticide use and safe handling.

Although the current analysis cannot claim to quantify the true extent of a traders' influence on a farmers' pesticide use behavior, the results do suggest that in areas where the trader does have a significant role in the pesticide information chain, focusing efforts towards greater awareness of pesticide toxicity, training on use and safe handling and appropriate protection measures should take center stage. In the survey, $90 \%$ of the traders indicated the need for further instructions on pesticide use and handling and over 92\% indicated no protection measures were taken during the handling of pesticides. Thus the benefit of further extension is very apparent, not only for the sake of trader health, but also as this information is passed on to farmers. 


\section{Introduction}

Information on potential health hazards is important for use and safe handling reasons for both farmers and traders alike. Indeed, without a sufficient understanding of the risks involved, the exposed may not take appropriate protective measures, leading most likely to unfavorable outcomes. ${ }^{1}$ As this information is often concentrated in relatively few hands, such as pesticide companies, scientists and agricultural ministry officials, the dissemination of this information poses a daunting challenge due to the sheer number and varying literacy rates of the ultimate users. This is particularly the case in developing countries where limited access to information and illiteracy can lead to serious bottlenecks in adequately transferring this information.

One cost-effective approach would be to increase awareness and training at the wholesaler or retailer level, where the effort has its greater reach. Recent studies also indicate that the retailer is extremely important for the user's selection of pesticide, recommended dosage and safe handling information. Given this role, it is important to understand the retailers' (traders') health risk perception of pesticides and perhaps even more importantly, what shapes this perception.

In this paper, we randomly selected and interviewed 110 pesticide traders across Bangladesh with structured questionnaires containing information on the nature of the pesticide shop; pesticide log \& sales; traders' characteristics; their knowledge of pesticides and sources of information, precautions and damage-averting behavior along with any associated health effects. From their responses we developed a two-equation model of risk perception - one equation comprised of factors affecting health impairment and a second capturing traders' health risk perception. The determining factors were grouped into variables representing a traders' exposure to pesticides, socio-economic status (knowledge and others) as well as current health impairment status.

\footnotetext{
1 The indiscriminate use of toxic synthetic pesticides in agriculture has caused serious problems to human health in many developing countries during the past three decades. The World Health Organization (WHO) and the United Nations Environment Program estimate that pesticide poisoning injures between one and five million agricultural workers per year (WRI, 1998). At least 20,000 workers die from exposure every year, the majority in developing countries (WHO, 1990; Kishi et al., 1995; Pimental et al., 1992; Rosenstock et al., 1991).
} 
Our analysis indicates that actual health impairment status, pesticide toxicity, average number of hours spent in the shop per day, as well as the interaction between the most harmful pesticides and training received in pesticide use and handling, are significant factors impacting traders' health risk perception of pesticides. Health impairment status is significantly affected by pesticide toxicity, exposure in terms of number of years spent in pesticide business, trader's age, and the interaction between the most harmful pesticides and training received in pesticide use and handling.

The present study contributes to the literature in several ways. Firstly, studies on the misperception of pesticide toxicity tend to be quite rare. Secondly, to the best of our knowledge, studies of the health effects of pesticide exposure on traders are also nonexistent in the literature, with most concentrating only on farmer health. ${ }^{2}$ Thirdly, although many may consider the relationship between a traders' perception of pesticide risks and health status rather obvious, this study provides a more rigorous test of that hypothesis.

The remainder of the paper is organized as follows. In Section 2 we describe the trend in pesticide use and the associated problems in Bangladesh. In Section 3 we present the survey, and in Section 4 a description of the dataset. Models, along with econometric findings, are documented in Section 5. In Section 6 we conclude and offer the implications of our findings.

\section{Pesticide use in Bangladesh at a glance}

As in many developing countries, Bangladesh has promoted the use of pesticides to expand agricultural land and increase output per acre. ${ }^{3}$ As a consequence of this expansive policy, pesticide use has more than doubled since 1992, rising from 7,350 metric tons to 16,200 metric tons in 2001. An FAO analysis of pesticide composition

\footnotetext{
2 This is particularly true in developing countries where even pesticide-related health studies are few in number (Ante and Pingali, 1992; Crissman et al., 1994; Dung and Dung, 2003; Pingali et al., 1994).

${ }^{3}$ Promotional activities have included extension services and significant subsidies (Rasul and Thapa, 2003; Hossain, 1988).
} 
revealed high shares of toxic chemicals which have known to cause cancer, genetic damage, fetal damage, and severe allergic responses in exposed populations (for example, carbamates and organophosphates in insecticides, and dithiocarbamates and inorganics in fungicides ) (Zahm, Ward and Blair, 1997).

Many pesticides used in Bangladesh are also banned or restricted under international agreements (Meisner, 2004; NOVIB, 1993; SOS-arsenic.net, 2004; SUNS, 1998). Pesticide suppliers in Bangladesh even continue to sell the 12 particularly controversial pesticides known by activists campaigning worldwide as the "dirty-dozen" (SUNS, 1998); SOS-arsenic.net, 2004). In addition, several studies have shown that inadequate product labeling and users' lack of information have lead to widespread overuse and misuse of dangerous pesticides. Anecdotal evidence suggests that the consequence of these practices are numerous, with pesticide poisonings abound (Ramaswamy, 1992). Although monitored health data on the effects of pesticides is not available in Bangladesh ${ }^{4}$ projections suggest an annual incidence of organophosphate poisoning alone is as high as 900/100,000 population (World Bank estimate, 2004). ${ }^{5}$

\section{The survey of traders}

\section{Background of the supply chain}

Bangladesh does not produce any active ingredients, it only imports and formulates. The marketing channel of pesticides in Bangladesh consists of pesticide companies, distributors, wholesalers, wholesaler-cum-retailers, retailers and farmers (Sabur and Moila, 2000). At the top, there exist approximately 66 officially registered companies, with 6 of these being multinational in nature. Distributors buy almost all of their products from pesticide companies. However, the pesticide companies also directly sell to wholesalers. Distributors, in turn, sell their products to the wholesalers-cum-retailers, retailers and large farmers. Wholesalers sell to retailers as well as farmers. Retailers, in turn, sell their product to farmers, but farmers frequently buy directly from the

\footnotetext{
${ }^{4}$ The 1999 DGHS data, produced by the Health Information Unit of DGHS, indicates that over 30,000 cases of poisoning were reported in 1997, however, they do not classify information by the source of poisoning.

${ }^{5}$ The comparable figure for the US is $71 / 100,000$.
} 
distributors as well as wholesalers. A simplified representation of these channels is presented in Figure 1.

Figure 1. A simplified representation of pesticide marketing channels in Bangladesh

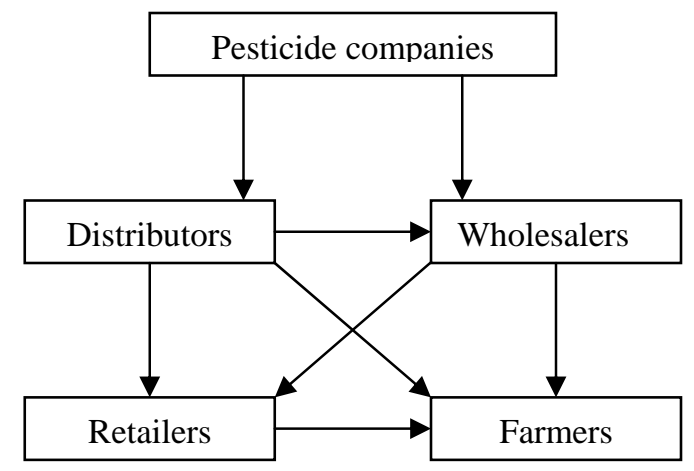

The survey, conducted in the summer 2003 by the World Bank, interviewed 110 pesticide traders (more or less equally divided between wholesalers and retailers) across 7 districts of Bangladesh. Table 1 and Figure 2 display the district distribution of traders in our sample. The survey collected detailed information from traders, including: 1) the name, location and nature of the shop; 2) trader's characteristic: age, ownership, nutritional status: weight/height; 3) pesticide log \& sales: trade name, chemical name, content quantity, price, best selling pesticides; 4) traders' knowledge of pesticides: information and training received on use and safe handling of pesticides; 5) precautions and damage-averting behavior; and 6) health effects. ${ }^{6}$ To minimize reporting bias, the survey was implemented under the agreement that the team would not reveal the identity of the trader companies surveyed on the respondents who participated.

\footnotetext{
${ }^{6}$ The survey was designed and supervised by the World Bank team, and conducted by the Development Policy Group in Bangladesh.
} 
Table 1. \& Figure 2. Regional distribution of survey respondents.

\begin{tabular}{lc}
\hline District & No. traders \\
\hline Chittagong & 10 \\
Comilla & 20 \\
Jessore & 20 \\
Kishoreganj & 10 \\
Rajshahi & 20 \\
Rangpur & 20 \\
Dhaka & 10 \\
\hline Total & 110 \\
\hline
\end{tabular}

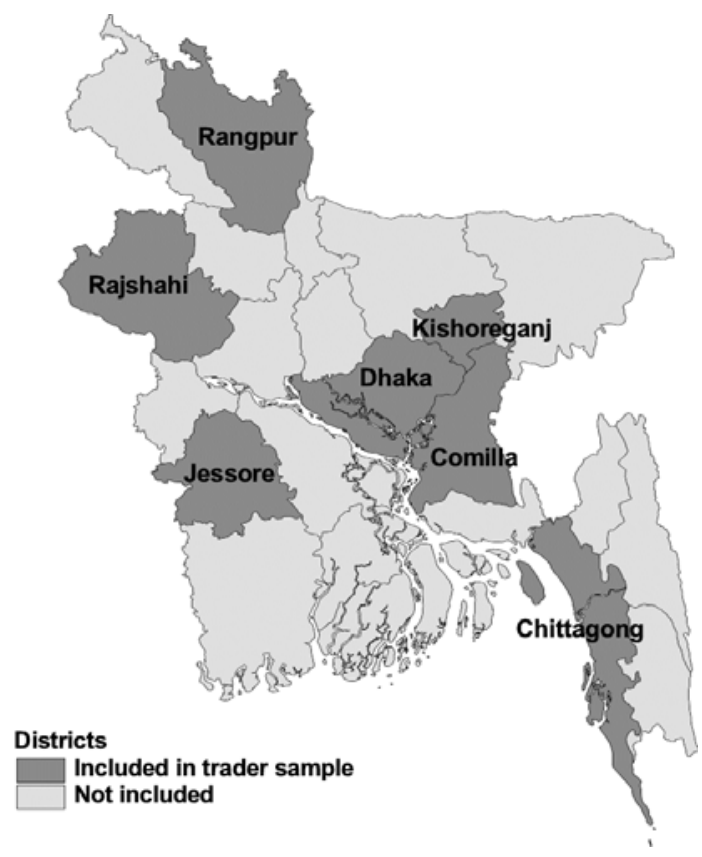

\section{Data}

\section{Trader characteristics}

Of the 110 traders surveyed, $87.3 \%$ of the traders own their shops, average 35 years in age (range 17-70 years), and all were male. Responses further revealed that the number of years the traders were in pesticide-related business varies widely from less than one year to 28 years, with an average of 9 years. ${ }^{7}$ The number of daily hours spent dealing with pesticides also varies from 1 to 24 hours, with an average duration of 10 hours.

\section{Pesticides in stock}

In terms of the number of pesticides available for purchase, there were a total of 150 formulations (using 62 different active ingredients) on the shelves. Classifying these by the WHO risk classification system, on average, 7\% are extremely hazardous (WHO class I), 66\% very hazardous (WHO class II), 11.2\% moderately hazardous (WHO class III) and $16 \%$ are low risk. Traders reported that most popular pesticides were formulations containing Cypermerthrin (WHO II), Chlorpyrifos (WHO II), Malathion

\footnotetext{
${ }^{7}$ This distribution is skewed, with 95\% of traders having at least 20 years of experience in the pesticiderelated business.
} 
(WHO III), Diazinon (WHO II), Fenvalerate (WHO II), Cartap (WHO II), and Dimethoate (WHO II).

In regards to shipment of pesticides to the shops, it was reported that $60 \%$ are delivered by pesticide companies directly, with the remaining $40 \%$ (most likely) picked up by the traders themselves. Up to $20 \%$ of the shipments arrive at the shop damaged, unsealed or broken, however only $<1 \%$ of traders $(0.05 \%)$ actually admitted to repackaging the contents.

\section{Training, averting behavior and perception}

As traders work, and surround themselves, with the substances, they are naturally exposed to the toxicity of the chemicals. Exposure to pesticides can lead to an array of health effects, depending on the pesticide's toxicity and the dose absorbed by the body. ${ }^{8}$ However, the health effects of pesticide use can often be reduced significantly by averting behavior - wearing protective clothing (Cropper, 1994) and exercising precaution. The extent of adverting behavior of a trader, in turn, depends, on the perception of risk and training received on safe handling of pesticides. In our survey, although $72 \%$ traders reported receiving at least some basic training on use of pesticides and safe handling ${ }^{9}, 92 \%$ openly admitted that they do not take any protective measures during the handling of pesticides.

To measure a trader's perception of health risk, two questions were asked, "whether the trader thought that pesticide handling and/or exposure, overall, has any negative short- or long-term impacts on their health". The results are summarized in Table 2. Perception was then constructed as equal to one if the respondent replied "Some, Large, or Fatal Effects" for either short or long-term impact (0 otherwise). Note those who

\footnotetext{
${ }^{8}$ For pesticides with high acute toxicity, exposure can produce intoxication symptoms within minutes or hours, and these acute effects run from mild headaches and flu like symptoms, to skin rashes, to blurred vision, and other neurological disorders (World Resources, 1998-99). In addition, prolonged exposure to pesticides can cause many chronic serious health effects: cardiopulmonary problems, neurological and haematological symptoms, and adverse dermal effects (Davies, Freed, and Whittemore, 1982; Spear, 1991). ${ }^{9}$ The dominant source of information on pesticide use and handling was by the pesticide supplier or company (67.27\%), followed by the Agricultural Ministry (19.09\%) and "self" (10.91\%).
} 
responded "Do Not Know" were disregarded. As constructed, 32\% of the survey traders indicated at least some effect.

Table 2. Frequency of response to short-and long-term impacts of pesticide exposure

\begin{tabular}{lcc}
\hline Response & Short-term impacts & Long-term impacts \\
\hline Don't know & - & - \\
No effect & - & - \\
Little effect & 42 & 31 \\
Some effect & 21 & 23 \\
Large effects & 13 & 22 \\
Fatal effects & 5 & 6 \\
\hline
\end{tabular}

\section{Health effects}

A detailed medical examination of sample traders was beyond the scope of the study. Instead, our analysis relied solely on self-assessed/reported health effects. ${ }^{10}$ Among the traders surveyed, 54\% reported frequent health problems such as eye irritation, headaches, dizziness, vomiting and skin effects (see Appendix for details). These symptoms have been associated with acute poisoning (extension Toxicology Network, 2004). A health effects variable was then constructed using the prevalence of these ailments. The variable was coded 1 if the respondent reported any one of these symptoms after handling pesticides and 0 otherwise.

\section{Determinants of trader's health perception}

\section{The model}

To model trader perception, we used a bivariate probit framework with health effects as an endogenous dummy variable. This method belongs to the general class of simultaneous equations systems first explored by Heckman (1978), and extended by Maddala (1983) to include recursive dichotomous choice models. The bivariate probit model with an endogenous dummy has been shown to be the appropriate inference tool

\footnotetext{
${ }^{10}$ Are self-reported health effects a credible measure? Detailed information for pesticide traders is virtually non-existent, however, medical tests of the farming population in other Asian countries may be indicative. Several clinical studies conducted on rice and vegetable farmers in Indonesia, Philippines, and Vietnam revealed 58\%-99\% of the farmers exposed to pesticides had at least one health effect (Xuyen et al., 1998; Kishi et al., 1995; Antle and Pingali, 1994). This evidence suggests that the degree of upward bias, if at all in a self-assessment health effects in Bangladesh (traders) may not be large.
} 
when there are sufficient reasons to consider a dependent binary variable as simultaneously determined with a dichotomous regressor (Fabbri, Monfardini and Radice, 2004). The structure of the model follows a two-equation form where the estimation outcome of the first equation is used as a regressor in the second equation as follows:

$$
\begin{aligned}
& y_{1 i}^{*}=\beta_{1} x_{1 i}+u_{1 i} \\
& y_{2 i}^{*}=\delta y_{1 i}+\beta_{2} x_{2 i}+u_{2 i}
\end{aligned}
$$

where $y_{1 i}^{*}$ and $y_{2 i}^{*}$ are latent variables, and $y_{1 i}$ and $y_{2 i}$ are the observed dichotomous variables following the rule:

$$
\left\{\begin{array}{l}
y_{k i}=1, \text { if } y_{k i}^{*}>0 \\
y_{k i}=0, \text { otherwise }
\end{array}\right.
$$

where $k=1,2 ; \quad i=1,2, \ldots, n$ represents the individual; $x_{1 i}$ and $x_{2 i}$ are vector of exogenous variables; $\beta_{1}$ and $\beta_{2}$ are parameter vectors; $\delta$ is a scalar parameter and the error terms are assumed to be independently and identically distributed as bivariate normal:

$$
\left(\begin{array}{l}
u_{1 i} \\
u_{2 i}
\end{array}\right) \sim \operatorname{IIDN}\left(\left[\begin{array}{l}
0 \\
0
\end{array}\right],\left[\begin{array}{ll}
1 & \rho \\
\rho & 1
\end{array}\right]\right)
$$

with $\rho$ as the degree of correlation between the unobservable explanatory variables, $u_{1 i}$ and $u_{2 i}$, of the two equations in (1). If $\rho \neq 0$, parameter identification in the second equation requires that $x_{2 i}$ contain at least one variable not contained in $x_{1 i}$ (Maddala, 1983; Wilde, 2000). The test for exogeneity, $\rho=0$, can be carried out using a likelihood ratio, Wald or Lagrange Multiplier test (Greene, 2003; Fabrici, Monfardini and Radice, 2004). Model (1) is estimated by maximum likelihood (ML), however, if we cannot reject $\rho=0$, then the two equations can be estimated separately by probit ML methods.

For the empirical model, we first specified the health effects equation relating to the first equation in (1) above, and simultaneously modeled trader's health risk perception using the second equation in (1). According to the medical literature, the type and severity of pesticide poisoning depends on: (a) the toxicity of the pesticide, (b) the amount of pesticide involved in the exposure, (c) the route of exposure, and (d) the 
duration of exposure (Extension Toxicology Network, 2004). ${ }^{11}$ The health impairment equation took these factors into account, along with the number of years in business, experience, nutritional status, smoking habits and location. Physical amounts, toxicity and duration of exposure are expected to be positively related to the prevalence of becoming sick, as are the number of years in business and smoking habits. Experience is expected to be negatively correlated with health impairment, while the sign on nutritional status can be in either direction. ${ }^{12}$ A traders' health risk perception is specified as a function of health effects, the degree of highly toxic stock, time in the shop, training and source of information. As perception is defined as whether the trader believes that the pesticides they handle are responsible for short- or long-term health effects $(=1)$, we expect actual health impairment (sickness), pesticide amount, toxicity, time in the shop and training to be positively correlated with risk perception.

Two interaction variables were also added to each equation to capture the joint effect between the toxicity of pesticides and training in safe handling as well as toxicity and the use of protective measures while loading pesticides. The interaction term between toxicity and training may have a positive (negative) sign in the health effects equation if the toxicity (training) effect is larger than the training (toxicity) effect. In the second equation, we expect the interaction terms to be positive as increases in either toxicity or training will increase a traders' perception of hazardous pesticides. The second interaction term between toxicity and protective measures is expected to be negative in the health equation and positive in the perception equation. Model (4) below summarizes the empirical relationship based on Model (1). Variable definitions are provided in Table 3.

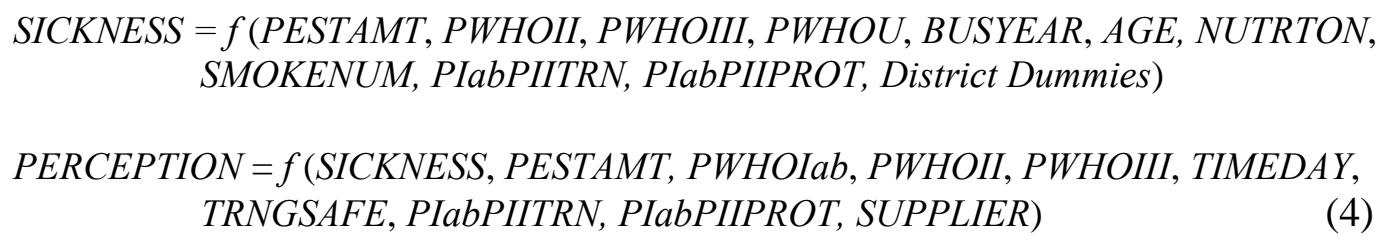

\footnotetext{
11 The route of exposure was not directly proxied in the model.

12 The sign would be negative if the respondent had a very low weight to height ratio (i.e. malnourished), and positive if a high ratio (i.e. obese).
} 
Table 3. Variable description

\begin{tabular}{|c|c|}
\hline Variable & Description \\
\hline SICKNESS & $\begin{array}{l}=1 \text { if trader reported any eye irritation, headache, dizziness, vomiting, diarrhea, fever, } \\
\text { convulsion, shortness of breath or skin irritation; = } 0 \text { otherwise }\end{array}$ \\
\hline \multirow[t]{2}{*}{ PERCEPTION } & $\begin{array}{l}=1 \text { if trader reported "Some, Large or Fatal effects" for short- or long-term health } \\
\text { impacts of pesticides; }=0 \text { otherwise }\end{array}$ \\
\hline & Exposure \\
\hline PESTAMT & Pesticide amount in stock (kilograms) \\
\hline PWHOIab & $\begin{array}{l}\text { Percentage of pesticide stock that is classified as WHO category Ia or Ib (extremely or } \\
\text { highly hazardous) }\end{array}$ \\
\hline PWHOII & $\begin{array}{l}\text { Percentage of pesticide stock that is classified as WHO category II (moderately } \\
\text { hazardous) }\end{array}$ \\
\hline PWHOIII & $\begin{array}{l}\text { Percentage of pesticide stock that is classified as WHO category III (slightly } \\
\text { hazardous) }\end{array}$ \\
\hline PWHOU & $\begin{array}{l}\text { Percentage of pesticide stock that is classified as WHO category U (unlikely to present } \\
\text { any acute hazard in normal use) }\end{array}$ \\
\hline PWHOUnk & Percentage of pesticide stock that is not classified by WHO (dropped in regression) \\
\hline BUSYEAR & Number of years in business \\
\hline TIMEDAY & $\begin{array}{r}\text { Average number of hours spent in shop per day } \\
\text { Socio-economic }\end{array}$ \\
\hline NUTRTON & Nutritional ratio of weight/height \\
\hline AGE & Age in years \\
\hline TRNGSAFE & $=1$ if trader received training on pesticide use and safe handling; $=0$ otherwise \\
\hline PROTLOAD & $=1$ if protective measures were taken during loading; $=0$ otherwise \\
\hline \multirow[t]{2}{*}{ SUPPLIER } & $\begin{array}{l}=1 \text { if the main source of pesticide use and safe handling information is from the } \\
\text { supplier; }=0 \text { otherwise }\end{array}$ \\
\hline & Interaction terms \\
\hline PIabPIITRN & Product of pesticide toxicity (PWHOIab + PWHOII) and TRNGSAFE \\
\hline \multirow[t]{2}{*}{ PIabPIIPROT } & Product of pesticide toxicity (PWHOIab + PWHOII) and PROTLOAD \\
\hline & Other controls \\
\hline CHITTAGONG & $=1$ if the trader is located in the district of Chittagong; $=0$ otherwise \\
\hline COMILLA & $=1$ if the trader is located in the district of Comilla; $=0$ otherwise \\
\hline JESSORE & $=1$ if the trader is located in the district of Jessore; $=0$ otherwise \\
\hline RAJSHAHI & $=1$ if the trader is located in the district of Rajshahi; $=0$ otherwise \\
\hline RANGPUR & $=1$ if the trader is located in the district of Rangpur; $=0$ otherwise \\
\hline DHAKA & $=1$ if the trader is located in the district of Dhaka; $=0$ otherwise \\
\hline
\end{tabular}

\section{Estimation results}

Model (4) was initially estimated as a bivariate probit with health effects as an endogenous dummy variable. Full information maximum likelihood estimates of the parameters are given in Table 4. The estimated value of $\rho=-0.691$ leads to a Wald test statistic of $(-1.10)^{2}=1.21<\chi_{1,0.10}^{2}=2.71$, thus the null hypothesis of $\rho=0$ is not rejected and the two equations can be estimated separately. We continue to present the individual results in Table 4. 
The results, to a large extent, are consistent with our expectations. Variables found to be significantly associated with the probability of traders' health impairment from pesticides are: pesticide toxicity, number of years spent in the pesticide business, traders' experience, the interaction between pesticide toxicity (WHO Ia or Ib + WHO II) and training in the safe handling of pesticides and traders in the district of Dhaka. ${ }^{13}$ Since the interaction term is positive, this implies that the toxicity effect has a greater effect than the training effect. The significant determinants of traders' health risk perception are: health impairment, pesticide toxicity, the average number of hours spent in shop per day, training and the interaction between toxicity and training. The negative sign on PWHOIII can be explained by the fact that this class of pesticide is relatively low in toxicity, thus traders who handle proportionately more of the class are less likely to believe that they are exposed to short- or long-term risks. The interaction term is incorrectly signed however, where one would expect that either an increase in toxicity or training to have a positive effect on risk perception.

To provide some further insights into these results, marginal effects were calculated for each of the single estimated equations (i.e., assuming $\rho=0$ ), and are presented in Table $5 .{ }^{14}$ It is worth noting that the marginal effects in the second equation consist of both direct and indirect effects. ${ }^{15}$

\footnotetext{
${ }^{13}$ A further regression, using PWHOIab as the dependent variable, revealed that Dhaka was the only significant location of WHO Ia and Ib pesticides. In terms of overall market development and external reach, the evidence suggests that Dhaka is more active in the most toxic pesticides.

${ }^{14}$ The marginal effects of the interaction term were calculated using the methodology developed by Ai and Norton, 2003.

${ }^{15}$ Indirect effects exist since the variable SICKNESS in the perception equation is also a function of similar variables that appear directly in the second equation.
} 
Table 4. Estimation results (t-statistics in parenthesis)

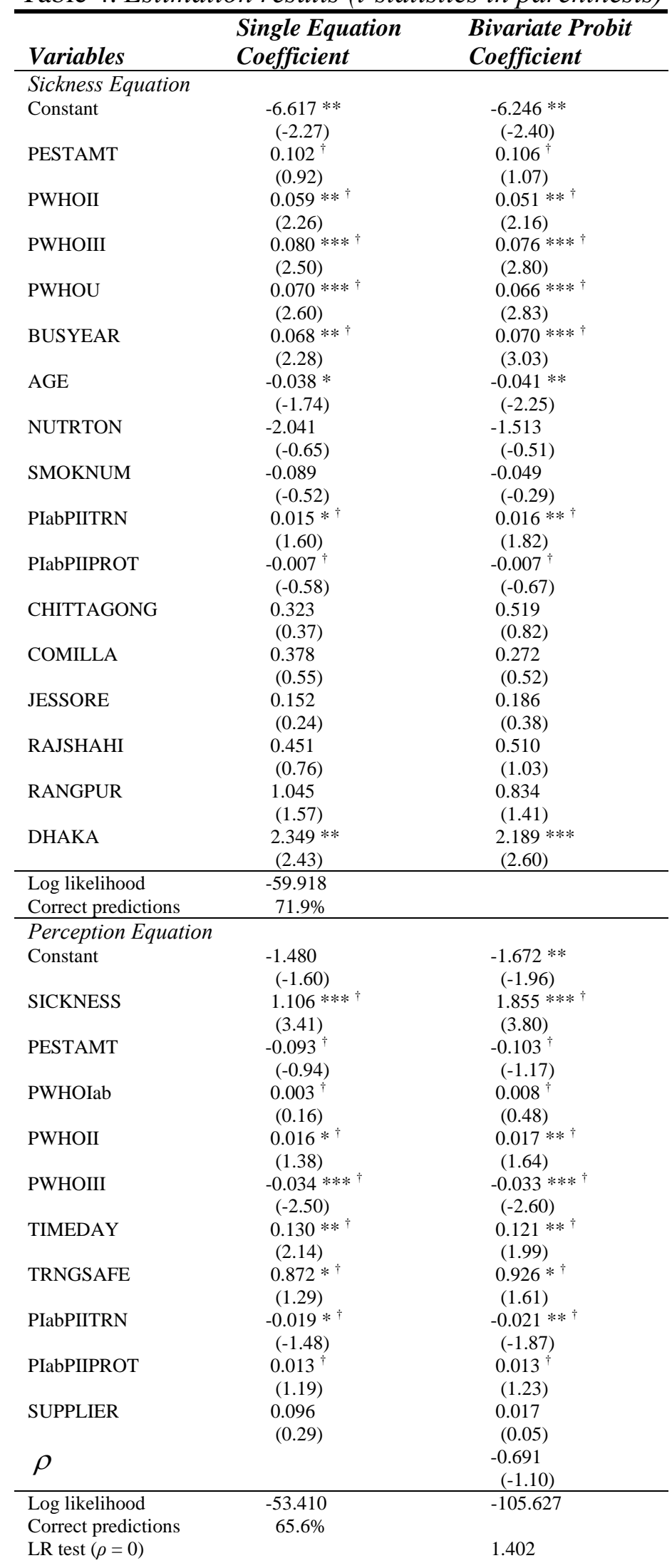




$$
\begin{aligned}
& \text { Wald }(\rho=0) \\
& \begin{array}{l}
\mathrm{N}=96 \\
\text { Note: } \begin{array}{l}
\dagger \\
*
\end{array} \\
\quad, * *, * * * \text { significance based on a 1-tailed t-test; }
\end{array}
\end{aligned}
$$

Pesticide toxicity, by class, has a positive impact on the probability of falling sick. The effect is quite similar across the three toxicity levels, where a $1 \%$ increase in handling a particular toxicity class increases the probability of falling sick, on average, by $0.024 \%$. Traders who are in business one additional year are associated with a higher probability of falling sick, by 0.024 (or 2.4\%), however, older traders with more experience tend to have a lower probability of falling sick (0.013) (or 1.3\%). The positive coefficient on the interaction term between hazardous pesticides and training has a positive overall effect on the probability of sickness of $0.005 \%$. However, this may also imply that the training content received by this sample of traders was relatively ineffective in communicating the relative risk of alternative pesticides. ${ }^{16}$ Although of

\begin{tabular}{|c|c|c|c|c|}
\hline Variables & Direct effect & Indirect effect & Total effect & Nature of variable \\
\hline \multicolumn{5}{|c|}{ Sickness Equation } \\
\hline PESTAMT & 0.035 & & 0.035 & Continuous \\
\hline PWHOII & $0.020 * *$ & & $0.020 * *$ & Continuous \\
\hline PWHOIII & $0.028 * * *$ & & $0.028 * * *$ & Continuous \\
\hline PWHOU & $0.024 * * *$ & & $0.024^{* * *}$ & Continuous \\
\hline BUSYEAR & $0.024 * *$ & & $0.024 * *$ & Continuous \\
\hline AGE & $-0.013^{*}$ & & $-0.013^{*}$ & Continuous \\
\hline NUTRTON & -0.708 & & -0.708 & Continuous \\
\hline SMOKNUM & -0.031 & & -0.031 & Continuous \\
\hline PIabPIITRN & $0.005 *$ & & $0.005^{*}$ & Continuous \\
\hline PIabPIIPROT & -0.002 & & -0.002 & Continuous \\
\hline \multicolumn{5}{|c|}{ Perception Equation } \\
\hline SICKNESS & $0.397 * * *$ & & $0.397 * * *$ & Binary endogenous \\
\hline PESTAMT & -0.037 & 0.014 & -0.023 & Continuous \\
\hline PWHOIab & 0.001 & & 0.001 & Continuous \\
\hline PWHOII & $0.006^{*}$ & $0.008^{* *}$ & $0.014^{*}$ & Continuous \\
\hline PWHOIII & $-0.013 * * *$ & $0.011^{* * *}$ & $-0.002 * * *$ & Continuous \\
\hline TIMEDAY & $0.051 * *$ & & $0.051 * *$ & Continuous \\
\hline TRNGSAFE & $0.337 *$ & & $0.337 *$ & Binary \\
\hline
\end{tabular}
correct sign, the impact of the interaction between pesticide toxicity (WHO Ia or Ib + WHO II) and protective measures during loading is not statistically significant. ${ }^{17}$

Table 5. Marginal effects of trader health risk perception model

\footnotetext{
${ }^{16}$ An overwhelming $90 \%$ of the traders pointed out the need for further instructions on pesticide use and handling.

${ }^{17}$ The survey reveals that $92 \%$ of traders did not use any protective measure during loading.
} 


\begin{tabular}{lcccl} 
PIabPIITRN & $-0.008^{*}$ & $0.002^{*}$ & $-0.006^{*}$ & Continuous \\
PIabPIIPROT & 0.005 & -0.001 & 0.004 & Continuous \\
SUPPLIER & 0.037 & & 0.037 & Binary \\
\hline
\end{tabular}

The significant marginal effects from the perception equation include sickness, pesticide toxicity, time spent in the shop, training and the interaction effect. Health impairment has the most sizable direct impact on trader's perception, followed by training, where traders who fell sick were $39.7 \%$ more likely to view the pesticide as hazardous (perception=1). Those receiving training were $33.7 \%$ more likely to view the pesticides as hazardous. Higher proportional use of WHO II pesticides increases risk perception by $0.014 \%$, whereas higher use of WHO III reduces risk perception by $0.002 \%$. In regards to the time spent in the shop, a one hour increase increases a traders' perception of health risk by 0.051 (or 5.1\%). The interaction term, although found to be negatively signed in the regression, has an overall effect of decreasing risk perception by $0.006 \%$.

\section{Summary and conclusion}

Systematic studies of pesticide exposure on trader's health and health risk perception are scarce in developing countries. Drawing on a new survey conducted in Bangladesh, this paper is an attempt to address this gap. To model trader health risk perception, we initially used a 2-equation, bivariate probit framework with health impairment effects as an endogenous dummy variable. Wald and likelihood ratio tests rejected the presence of endogeneity, and thus the two equations were estimated separately.

Even casual inspection during the survey revealed that traders work, and surround themselves, with toxic substances. When questioned, 54\% of the traders reported frequent health symptoms commonly associated with acute pesticide poisoning such as eye irritation, headaches, dizziness, vomiting and skin effects. Yet, 92\% openly admitted that they do not take any protective measures during handling of pesticides. The probit analysis strongly indicates that the persistent exposure to toxic pesticides increases the probability of sickness. It is widely known that the health effects of pesticide use can be reduced significantly by averting behavior - such as wearing gloves, eye glasses or a mask while handling pesticides and washing hands after touching pesticides. There is an 
urgent need for active promotion of suitable averting behavior and hygienic practices among pesticide traders in Bangladesh. As one in five pesticide shipments arrive at the shop damaged, unsealed or broken, the packaging of pesticides should also be carefully reexamined, along with the adoption of improved international standards such as airtightness. In addition, since many of the serious pesticide-related health effects can be avoided if exposure is minimized, it is important to monitor traders with regular checkups and blood tests before the level of contamination leads to any serious illness (Extension Toxicology Network, 2004).

Our analysis indicates that the formal training and information on use and safe handling received when combined with pesticide toxicity (an interaction effect) has a positive impact on health impairment. This may provide evidence as to the effectiveness of the training received among the sample of traders surveyed. As $90 \%$ of the traders indicated the need for further instructions on pesticide use and handling, this result is not surprising. The information content of current training programs should be critically reviewed and/or revised to reflect any current informational gaps. Potential areas of improvement include more specific information on the health hazards of pesticides and averting behavior. In the design of training, it would also be advisable to include both farmers and traders to better reflect the needs of the final users. In light of limited resources available for such efforts, targeting such information programs at the traderlevel would perhaps be advantageous for two reasons. First, retailers would benefit from this information and take appropriate precautions to reduce their own health risk. Secondly, they may pass this information along to the farmer, and thus improve the farmers' understanding of pesticide handling and precautions.

\section{References}

Ai, C. and E. C. Norton (2003), 'Interaction Terms in Logit and Probit Models', Economics Letters 80: 123-129. 
Antle, J. M. and P. L. Pingali (1994), 'Pesticides, Productivity, and Farmer Health: A Philippine Case Study’, American Journal of Agricultural Economics 76: 418-430.

Crissman, C.C., D. C. Cole and F. Carpio (1994), 'Pesticide Use and Farmer Worker Health in Ecuadorian Potato Production', American Journal of Agricultural Economics 76: 418-430.

Cropper, M. (1994), 'Economic and Health Consequences of Pesticide Use in Developing Country Agriculture: Discussion’, American Journal of Agricultural Economics 76: 605607.

Davies, V., H. Freed, and F. W. Whittemore (1982), 'An Agromedical Approach to Pesticide Management: Some Health and Environmental Considerations’, Miami, Fla., USA: University of Miami School of Medicine in cooperation with the Agency for International Development (USAID) and Consortium of International Crop Protection.

Extension Toxicology Network (ECOTOXNET) (2004), 'Cholinesterase Inhibition', Toxicology Information Brief. Cornell University. Available at: http://pmep.cce.cornell.edu/profiles/extoxnet/TIB/cholinesterase.html

Dung, N.H and T. T. T. Dung (2003) 'Economic and Health Consequences of Pesticide Use in Paddy Production in the Mekong Delta, Vietnam', EEPSEA Research Reports, 39p, http://203.116.43.77/publications/research1/ACF124.html

Fabbri, D., C. Monfardini and R. Radice (2004), 'Testing Exogeneity in the Bivariate Probit Model: Monte Carlo Evidence and an Application to Health Economics', Department Working Paper No. 514. Department of Economics, University of Bologna, Italy.

Green, W. H. (2003), Econometric Analysis. Upper Saddle River: Prentice Hall. 
Heckman, J. (1978), 'Dummy Endogenous Variables in a Simultaneous Equation System’, Econometrica 46: 931-959.

Hossain, M. (1988), 'Nature and Impact of the Green Revolution in Bangladesh', Research Report No. 67. Washington DC: International Food Policy Research Institute.

Kishi, M., N. Hirschhorn, M. Qjajadisastra, L. N. Satterlee, S. Strowman and R. Dilts. (1995), 'Relationship of Pesticide Spraying to Signs and Symptoms in Indonesian Farmers’, Scandinavian Journal of Work \& Environmental Health 21: 124-133.

Maddala, G. S. (1983), Limited Dependent and Qualitative Variables in Econometrics. Cambridge: Cambridge University Press.

Meisner, C. (2004), 'Report of Pesticide Hotspots in Bangladesh', Report to the Canadian International Development Agency (CIDA). Mimeo. Washington DC: World Bank.

NOVIB (1993), 'Pesticides Misuse in Bangladesh’, The Pesticides News, No. 22, Dec. 1993. The Pesticides Trust. London, U.K.

Pimental, D., H. Acquay, M. Biltonen (1992), 'Environmental and Economic Costs of Pesticide Use', Bioscience 42, 750-60.

Ramaswamy, S. (1992), 'Pest Control and Environment', Notes for discussion at a seminar on environment and agriculture. Agriculturalist Association of Bangladesh, Dhaka, p.19.

Rasul, G. and G. Thapa (2003), 'Sustainability Analysis of Ecological and Conventional Agricultural Systems in Bangladesh’, World Development 31 (10): 1721-1741. 
Rola, A. C. and P. L. Pingali (1993), Pesticides, Rice Productivity, and Farmer's Health: an economic assessment. Washington DC: International Rice Research Institute, World Resources Institute.

Rosenstock, L., M. Keifer, W. E. Daniell, R. McConnell, K. Claypoole (1991), 'Chronic Central Nervous System Effects of Acute Organophosphate Pesticide Intoxication', Lancet 338: 223-227.

Sabur, S.A. and A. R. Molla (2000), 'Marketing and Economic Use of Pesticides: Impact on Crop Production', Bangladesh Agricultural University, Mymensingh, Bangladesh (mimeo).

SOS-Arsenic.net (2004), 'Agrochemicals: Imported Pollutants in Bangladesh', Available at: http://www.sos-arsenic.net/index.html.

SUNS (1998), 'Pesticide Overuse Takes Serious Turn in Bangladesh', Monday, Jan. 24, (Dhaka, Jan. 23 IPS/Tabibul Islam).

World Health Organization (WHO) (1990), Public Health Impact of Pesticides Used in Agriculture, 1990, New York: World Health Organization.

Wilde, J. (2000), 'Identification of Multiple Equation Probit Models with Endogenous Dummy Regressors’, Economics Letters 69: 309-312.

World Resources Institute, UNEP, UNDP, World Bank (1998), 'Environmental Change and Human Health', in World Resources 1998-99, New York: Oxford University Press.

Xuyen, K., N. C. Hoi and P. Q. Trung (1998), 'Occupational Environment and Skin Diseases in Pesticide Exposed Subjects in some Tea Farms in Vietnam', Presentation given at the Third National Scientific Conference on Occupational Health, December 45, 1998. Hanoi. 
Zahm, S. H., M. H. Ward and A. Blair (1997), 'Pesticides and Cancer', in M. Keifer, ed., Occupational Medicine: State of the Art Reviews, Vol. 12: Pesticides, Philadelphia: Hanley and Belfus, Inc., 269-289.

\section{Appendix. Health effects}

Among the most perceptible health problems encountered in the survey, eye effects, neurological effects (headache, dizziness), dermal effects and gastrointestinal tract effects (vomiting) were the most common; 16\% of the respondents reported irritation in the eyes, 21\% headaches, 6\% dizziness, 5\% skin irritation and 7\% vomiting after handling pesticides. The interviews further revealed that $30 \%$ of the respondents experienced multiple health effects, with the duration of ailment also being quite significant. Traders indicated an average duration of 7 hours in terms of eye irritation, 13 for headaches and 21 hours for dizziness (see Figure 3).

\section{Figure 3. Duration of Reported Ailments}

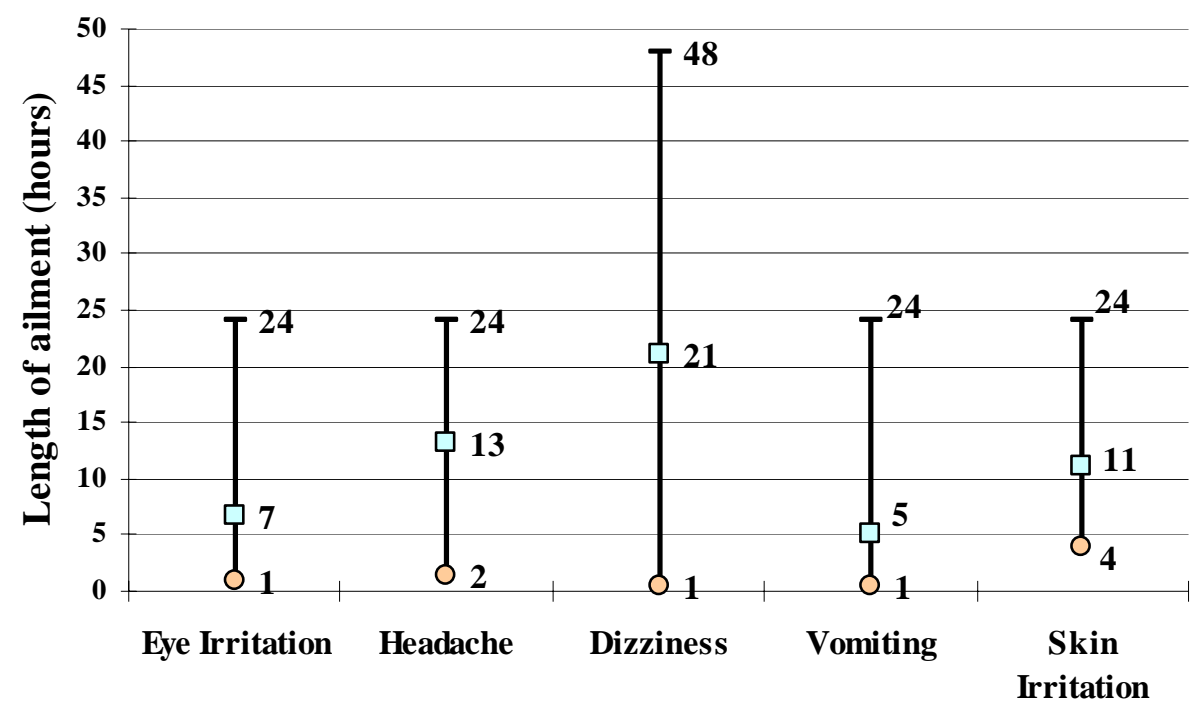

$\circ$ Min $\square$ Mean - Max 